\title{
Design and Development of Shell \& Tube Heat Exchanger for Beverage
}

\author{
Shravan H. Gawande ${ }^{1}$, Sunil D. Wankhede ${ }^{1}$, Rahul N. Yerrawar ${ }^{1}$, Vaishali J. Sonawane ${ }^{1}$, \\ Umesh B. Ubarhande ${ }^{2}$ \\ ${ }^{1}$ Department of Mechanical Engineering, M. E. Society's College of Engineering, Pune, India \\ ${ }^{2}$ Dy. Manager, PEM Design (R\&D), Alfa Laval (India) Ltd., Pune, India \\ Email: shgawande@gmail.com
}

Received July 26, 2012; revised September 2, 2012; accepted September 26, 2012

\begin{abstract}
In the first part of this paper, a simplified approach to design a Shell \& Tube Heat Exchanger [STHE] for beverage and process industry application is presented. The design of STHE includes thermal design and mechanical design. The thermal design of STHE involves evaluation of required effective surface area (i.e. number of tubes) and finding out $\log$ mean temperature difference [LMTD]. Whereas, the mechanical design includes the design of main shell under internal \& external pressure, tube design, baffles design gasket, etc. The design was carried out by referring ASME/TEMA standards, available at the company. The complete design, fabrication, testing and analysis work was carried out at Alfa Laval (India), Ltd., Pune-12. In the second part of this paper detail view of design optimization is presented by flow induced vibration analysis [FVA].
\end{abstract}

Keywords: Heat Exchanger; LMTD; TEMA; HTRI

\section{Introduction}

Heat Exchangers are devices used to enhance or facilitate the flow of heat. Every living thing is equipped in some way or another with heat exchangers. They are widely used in space heating, refrigeration, air conditioning, power plants, chemical plants, petrochemical plants, petroleum refineries, natural gas processing, and sewage treatment. The design of STHE including thermodynamic and fluid dynamic design, cost estimation and optimization, represents a complex process containing an integrated whole of design rules and empirical knowledge of various fields.

The design of STHE involves a large number of geometric and operating variables as a part of the search for heat exchanger geometry that meets the heat duty requirement and a given set of design constrains. A STHE is the most common type of heat exchanger in oil refineries and other large chemical processes, and is suited for higher-pressure applications. As its name implies, this type of heat exchanger consists of a shell (a large vessel) with a bundle of tubes inside it. One fluid runs through the tubes and the second runs over the tubes (through the shell) to transfer heat between the two fluids. A set of tubes is called a tube bundle which may be composed by several types of tubes e.g. plain, longitudinally finned, etc.

\section{Existing Industrial Scenario}

In industries, heat exchangers are used in industrial process to recover heat between two process fluids. Shell-and-tube heat exchangers are the most widely used heat exchangers in process industries because of their relatively simple manufacturing and their adaptability to different operating conditions. But nowadays numbers of industries are searching for effective and less time consuming alternatives of designing of shell-and-tube heat exchangers. As per literature and industrial survey it is observed that there is need of effective design options for STHE. This section explains the details of existing industrial scenario of design of STHE.

\subsection{Part A-Thermal Design}

The thermal design of STHE includes:

1) Consideration of process fluids in both shell and tube side;

2) Selection of required temperature specifications;

3) Limiting the shell and tube side pressure drop;

4) Setting shell and tube side velocity limits;

5) Finding heat transfer area including fouling factor.

\subsection{Part B-Mechanical Design}

The mechanical design of STHE includes: 
1) Selection of TEMA layout_-based on thermal design;

2) Selection of tube parameters such as size, thickness, layout, pitch, material;

3) Limiting the upper and lower design on tube length;

4) Selection of shell side parameters such as material, baffle spacing, and clearances;

5) Thermal conductivity of tube material;

6) Setting upper and lower design limits on shell diameter and baffle spacing.

As per literature and industrial survey at $\left[\mathrm{A}_{1} \& \mathrm{~A}_{2}\right]$ the design is carried out using in-house developed software for design and drafting. This dedicated software enables qualified engineers to accomplish complex design calculations complying strictly with the requisite international codes and standards. The software also generates fabrication drawings to scale and 3-D images of the Exchanger thereby giving warning of any foul-up/mis-match in nozzles, RF-Pads and in the dimensions of various components. Also an experienced team of design engineers undertakes thermal and mechanical design of complex heat exchangers and generate fabrication drawings to scale along with weights and estimates based on customer's specifications. These designs are optimized to arrive at an optimal size. After carrying out the design, the final output is in an AutoCAD drawing format (DWG) or DWF (Web format).

In this proposed work design, development \& testing of STHE is carried out. Along with the parameter considered as per [A1 \& A2], the software generated design was cross checked with manual design. Also vibration analysis is performed to optimize unsupported span of tube by using HTRI software.

The paper is organized as; detailed overview on work carried out by researchers is presented in Section 1 and Section 2 presents the existing industrial scenario of STHE design, Section 3 states the current problem definition \& objective, detailed design (thermal and mechanical design) and details of STHE are given in Section 4. Section 5 explores manufacturing of STHE, while Section 6 describes hydraulic testing of STHE and concluding remark is given in Section 7.

\section{Problem Definition \& Objective}

The problem presented in this paper is to design $\&$ develop a STHE, conforming to the TEMA/ASME [1-2] Standards, based on following Input Data:

1) Inlet \& Outlet Temperatures of fluids on Shell \& Tube Side,

2) Tube length $=10,000 \mathrm{~mm}$,

3) Tube $\mathrm{OD}=38.1 \mathrm{~mm}$,

4) Shell OD $=1350 \mathrm{~mm}$.

As per the requirement the objective of the preset work is to perform thermal and mechanical design of STHE using TEMA/ASME standards to reduce time.

\section{Design of STHE}

The design of STHE involves a large number of geometric and operating variables as a part of the search for an exchanger geometry that meets the heat duty requirement and a given set of design constrains. Usually a reference geometric configuration of the equipment is chosen at first and an allowable pressure drop value is fixed. Then, the values of the design variables are defined based on the design specifications and the assumption of several mechanical and thermodynamic parameters in order to have a satisfactory heat transfer coefficient leading to a suitable utilization of the heat exchange surface. The designer's choices are then verified based on iterative procedures involving many trials until a reasonable design is obtained which meets design specifications with a satisfying compromise between pressure drops and thermal exchange performances [3-10].

The details of shell and tube heat exchanger under consideration are shown in Table 1.

The details of STHE are shown in Table 1. Figure 1 shows the various major components of a typical STHE as listed below:

1) Connections

Table 1. STHE specification.

\begin{tabular}{cc}
\hline Parameter & Description \\
\hline Size (Dia./length) & $\varnothing 1336 / 10,000 \mathrm{~mm}$ \\
Surface area (eff.)/unit & $781.4 \mathrm{~m}$. sq. \\
Shells/unit & 1 \\
Heat exchanged, $(Q)$ & $5064.9 \mathrm{KW}$ \\
LMTD (Corrected) & $9.15^{\circ} \mathrm{C}$ \\
\hline
\end{tabular}

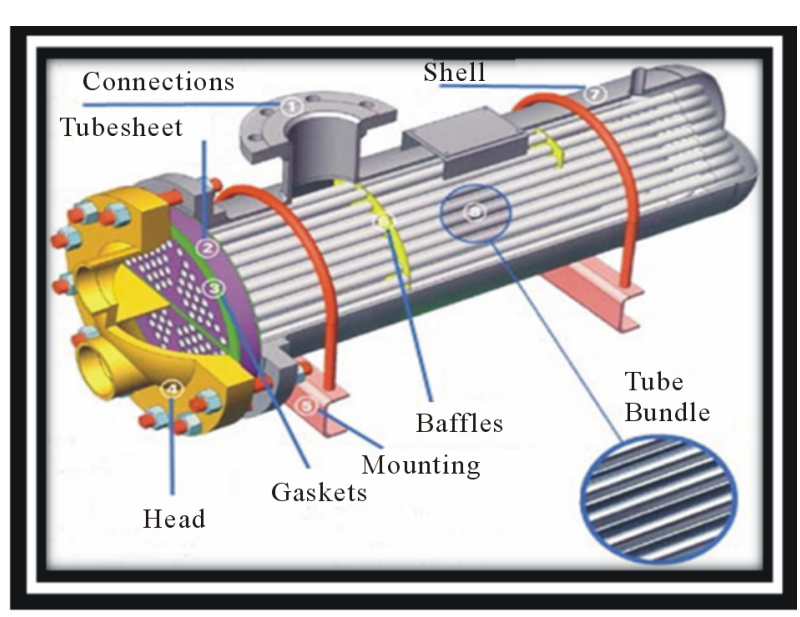

Figure 1. Major components of a typical STHE. 
2) Tube Sheet

3) Gasket

4) Head/Dish End

5) Mounting/Support

6) Baffles

7) Shell

8) Tube Bundle

\subsection{Part-A: Thermal Design}

\section{Design input:}

1) Mass flow rate $(\mathrm{m})$

2) Heat exchanged $(Q)$

3) Shell side inlet temperature $\left(t_{s i}\right)$

4) Shell side outside temperature $\left(t_{s o}\right)$

5) Tube side inlet temperature $\left(t_{t i}\right)$

6) Tube side outlet temperature $\left(t_{t o}\right)$

7) Transfer rate $(U)$

8) Tube outside diameter $\left(d_{o}\right)$

9) Length of tube $(L)$

\section{Output:}

1) LMTD (Log Mean Temp. Difference) $\left(\theta_{\mathrm{m}}\right)$ :

$$
\begin{aligned}
\theta_{m} & =\left(\theta_{1}-\theta_{2}\right) /\left(\ln \left(\theta_{1} / \theta_{2}\right)\right) \\
& =\left(t_{s i}-t_{t i}\right)-\left(t_{s o}-t_{t o}\right) / \ln \left(\left(t_{s i}-t_{t i}\right) /\left(t_{s o}-t_{t o}\right)\right) \\
& =9.15 \mathrm{C} .
\end{aligned}
$$

2) Area (A):

$$
Q=U \times A \times \theta_{m} \text { where, } A=781.61 \mathrm{~m}^{2} .
$$

3) Number of Tubes (n):

$Q=U \times n \times \pi \times d_{o} \times L \times \Delta_{t}$ where, $n=660$ tubes.

\subsection{Part-B: Mechanical Design}

\section{Main Shell Design}

Design Input:

1) Internal design pressure $\left(P_{s}\right)$

2) External design pressure $\left(P_{e}\right)$

3) Shell outside diameter $(D)$

4) Joint efficiency for longitudinal joint $(K)$

5) Joint efficiency for circumferential joint $(E)$

6) Allowable Stress $(S)$

7) Element thickness $(t)$

8) Joint efficiency for outer longitudinal joint $\left(K_{o}\right)$

9) Shell outside diameter with allowance $\left(D_{s o}\right)$

10) Constant Factor $(B)$

\section{Output:}

Design under Internal Pressure:

- Required thickness due to internal pressure $\left(t_{r}\right)$ :

$$
=\left(P_{s} \times D \times K\right) /\left(2 \times S \times E-0.2 \times P_{s}\right)=4.92 \mathrm{~mm}
$$

- Max. allowable working pressure at given thickness

$$
=(2 \times S \times E \times t) /(K \times D+0.2 \times t)=7.99 \text { bar }
$$

- Max. allowable pressure, new and cold

$$
=(2 \times S \times E \times t) /(K \times D+0.2 \times t)=10 \text { bar }
$$

- Actual stress at given pressure and thickness,

$$
=\left(P_{s} \times R\right) /\left(S \times E-0.6 \times P_{s}\right)=4.94 \mathrm{~N} / \mathrm{mm}^{2}
$$

- Straight flange maximum allowable working pressure:

$$
=(S \times E \times t) /(R+0.6 \times t)=9.27 \text { bar }
$$

Design under external pressure:

- Maximum allowable external pressure (MAEP):

$$
\mathrm{MAEP}=B /\left(K_{o} \times D_{s o} / t\right)=2.76 \text { bar }
$$

\section{Tube Design \\ Design input:}

- Internal Design Pressure $\left(P_{t}\right)$

- Allowable stress at design Temperature $(S)$

- Outside diameter $\left(D_{o}\right)$

- Joint efficiency for Longitudinal joint $(E)$ Output:

- Required Tube Thickness:

$$
T_{r t 1}=\left(P_{t} \times D_{o}\right) /\left(2\left(S \times E+0.4 \times P_{t}\right)\right)=1.24 \mathrm{~mm}
$$

\section{Baffles and Spacing}

- Baffle type: Triple segmental

- Nominal shell ID: $1336 \mathrm{~mm}$

- Baffle spacing (Min.): segmental baffles should not be spaced closer than $1 / 5$ th of the shell ID or 2 " (51 $\mathrm{mm}$ ), whichever greater. However, special design considerations may dictate a closer spacing.

- Baffle spacing (center to center) $=570 \mathrm{~mm}$

- Spacing at inlet $=670.67 \mathrm{~mm}$

- Baffle thickness $=12.7 \mathrm{~mm}$

Tube Pitch

Tubes shall be spaced with minimum center to center distance of 1.25 times the outside diameter of the tube. When mechanical cleaning of the tubes is specified by the purchaser and the nominal shell diameter, minimum cleaning lanes of 1/4" $(6.4 \mathrm{~mm})$ shall be provided.

\section{Gasket}

The minimum width of peripheral ring gaskets for external joints shall be $3 / 8 "(9.5 \mathrm{~mm})$ for shell sizes through 23 " (584 mm) nominal diameter and 1/2" (12.7 $\mathrm{mm})$ for all larger sizes.

\section{Manufacturing of STHE}

In this section detail of manufacturing of STHE is explained as shown in Figures 2-5.

\subsection{Fabrication of Main Shell and Channel Shell}

The steps in fabrication of main shell and channel shell are stated as below; 


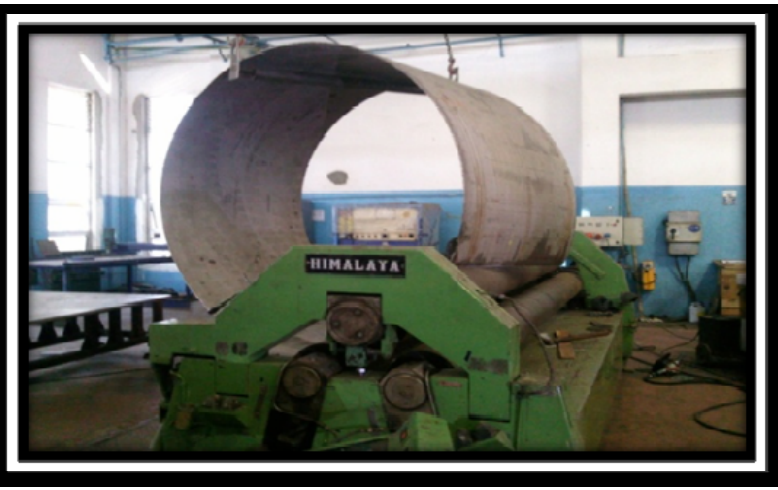

Figure 2. Rolling of shell.

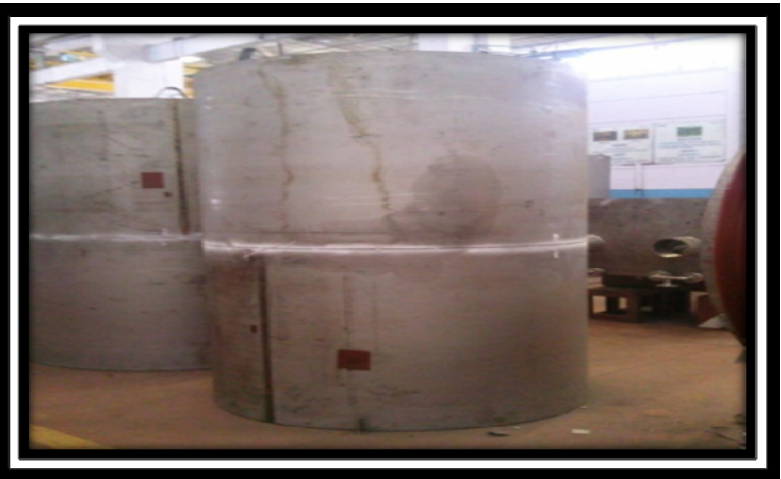

Figure 3. L-seam welding \& DP test.

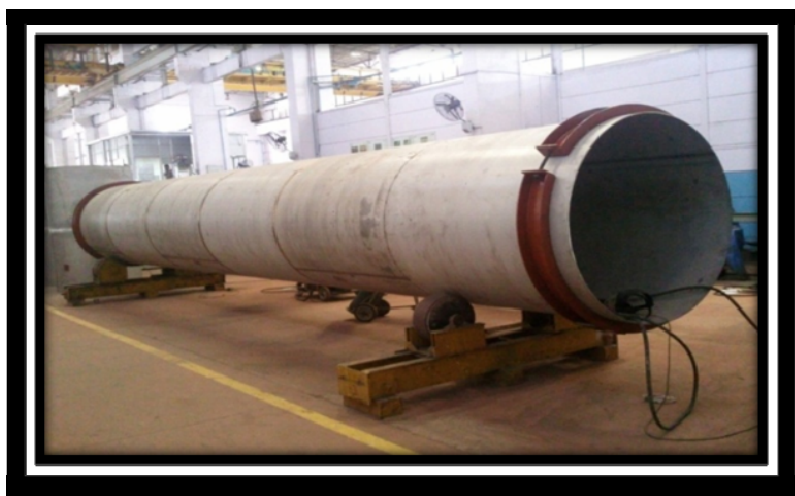

Figure 4. Joining of shell.

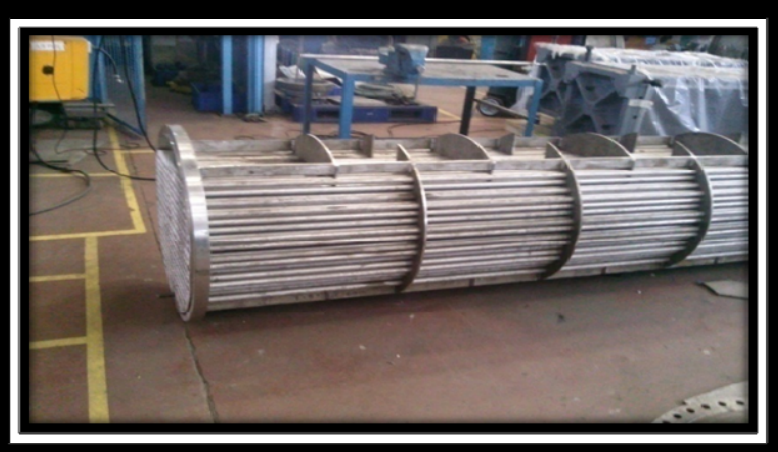

Figure 5. Tubes \& Baffles assembly.
- Material identification

- Marking

- Punching

- Cutting

- Grinding

- Edge preparation

- Rolling and L-seam fit up (Figure 2)

- L-seam welding (Figures 3 and 4)

- Back-chipping

- Die-penetrant (DP) Test (Figure 3)

\subsection{Channel Shell to Dish End \& Flange Fit-Up}

- Material identification

- Edge preparation

- Flange Fit-up and Welding

- Channel Shell Dish End Fit-up and Welding

\subsection{Tubes \& Baffles Assembly}

- Orientation marking

- Insertion of tie rods

- Insertion of spacers and baffles

- Insertion of tubes in the baffles

- Insertion of tube bundle assembly in the shell

\subsection{Tube-Sheet Fit-Up}

- Angular positioning of tube-sheet with respect to shell

- Welding of tube-sheet to shell

- Second tube-sheet fit-up

\subsection{Tube to Tube-Plate Joint}

- Length adjustment

- Tacking of the tubes

- Dye penetrant test

- Expansion of the tubes

\subsection{Channels to Main Shell Fit-Up}

- Gasket Positioning

- Bolting

\section{Hydraulic Testing}

\subsection{For Shell Side}

- Design pressure $(P)$

- Minimum stress ratio $\left(S_{h} / S\right)_{\min }$

- Hydraulic test pressure at the top $\left(P_{h t}\right)$ $=1.1 \times P \times\left(S_{h} / S\right)_{\min }$ $=5.72$ bar

\subsection{For Channel Side}

- Design pressure $(P)$ 
- Minimum stress ratio $\left(S_{h} / S\right)_{\min }=1$

- Hydraulic test pressure at the top $\left(P_{h t}\right)$

$$
=1.3 \times P \times\left(S_{h} / S\right)_{\min }
$$

$=6.76 \mathrm{bar}$

\section{Conclusion}

The design of STHE i.e. thermal and mechanical design was carried out using TEMA/ASME standards both manually and using software. It is found that design of STHE obtained by both approaches is very easy, simple, advance \& less time consuming as comparing to existing method used in different Indian industries [such $\mathrm{A}_{1} \&$ $\mathrm{A}_{2}$ ]. Manufacturing and hydraulic testing of STHE was carried out at Alfa Laval (India) ltd., Pune-12. The hydraulic test pressure at the top is found to be 6.76 bar.

\section{REFERENCES}

[1] TEMA, "Standards of the Tubular Exchanger Manufacturer's Association (TEMA)," 8th Edition, Section 1-5, 7-10, Tubular Exchanger Manufacturers Association, Inc., New York, 1999.
[2] ASME Section II, "For Material Specifications," 2004.

[3] ASME Section V, "For Non-Destructive Examination," 2004.

[4] ASME Section VIII, Division I, "Rules for Construction of Pressure Vessels," 2007.

[5] ASME Section IX, "For Welding \& Brazing Qualifications," 2004.

[6] Wolverine, "Wolverine Tube Heat Transfer Data Book," 2nd Edition, Wolverine Tube Inc., Decatur, 1984, pp. 60-71, 85-95.

[7] Dennis R. Moss, "Pressure Vessel Design Manual," 3rd Edition, Chapter 1-4, Elsevier, Amsterdam, 2003.

[8] R. K. Shah, "Fundamentals of Heat Exchanger Design," 2nd Edition, Chapter 1-5, Wiley, Hoboken, 2003. doi: $10.1002 / 9780470172605$

[9] R. Mukherjee, "Practical Thermal Design of Shell and Heat Exchangers," 2nd Edition, Chapter 1-5, 8, Begell House, Redding, 2004.

[10] S. T. M. Than, "Heat Exchanger Design," World Academy of Science, Engineering and Technology, Vol. 46, 2008, pp. 604-611.

\section{Appendix}

$\mathrm{A}_{1}$. JC Equipments Pvt. Ltd.

$\mathrm{A}_{2}$. TEMA India Ltd. 